\title{
THE “TEA CUP EFFECT" AND REMOVAL OF SUSPENDED SOLIDS FROM WATER
}

\author{
D.A. MASHAURI \\ University of Dar es Salaam Water Resources Engineering Department \\ P.O. Box 35131 Dar es salaam Tanzania \\ E-mails: mashauri@udsm.ac.tz
}

\begin{abstract}
Suspended solids problem in water is an issue as old as water treatment itself. Suspended solids can be causative to eroding through abrasion of impellers, pump casings, pipes and other water works related appurtenances. It is therefore appropriate that suspended solids must be removed as early as possible in the water works treatment facilities. It is usually done at the river/lake intakes to reduce the coarse particulate matter that would otherwise adversely affect the water works thereafter. The fine particles that will escape the entrapment at the intake works would therefore require further and more effective system that would remove this fraction. By and large this removal process is achieved by chemically aided process such as coagulation/flocculation unit operation. This process is expensive and demands high level trained personnel to man them. In the same vein then a simple and effective system is proposed. This is a swirl or grit removal system that does not need any chemicals, moving parts or even highly trained personnel to operate them. This paper is looking at the theory of the "Tea Cup Effect" and how it has been used in practice to remove or reduce suspended solids from water. The paper gives some examples where such devices have been used and how effective they have been.
\end{abstract}

Key words: Tea-cup-effect, vortex motion, mantle, shear zone, suspended solids, removal efficiency.

\section{INTRODUCTION}

\section{The "Tea Cup Theory"}

Consider a flat bottomed glass and a few tea leaves in water can demonstrate part of this process at work. After stirring tea leaves swirl round the peripheries of the glass, as the speed of rotation declines the solid particles move to the centre and settle in the middle of the base.

Indeed Figure 1 above is a simplified explanation of a highly complex process. But it suffices to say that the Figure shows some of the forces inaction. As it would be explained later, at low velocities the central column rotates much slower and out of ratio with the remainder of the liquid. The difference in velocities creates a "Shear Zone" around the outer edge of the column as such induces settleable solids down to form a doughnut shaped ring of solids at the bottom..

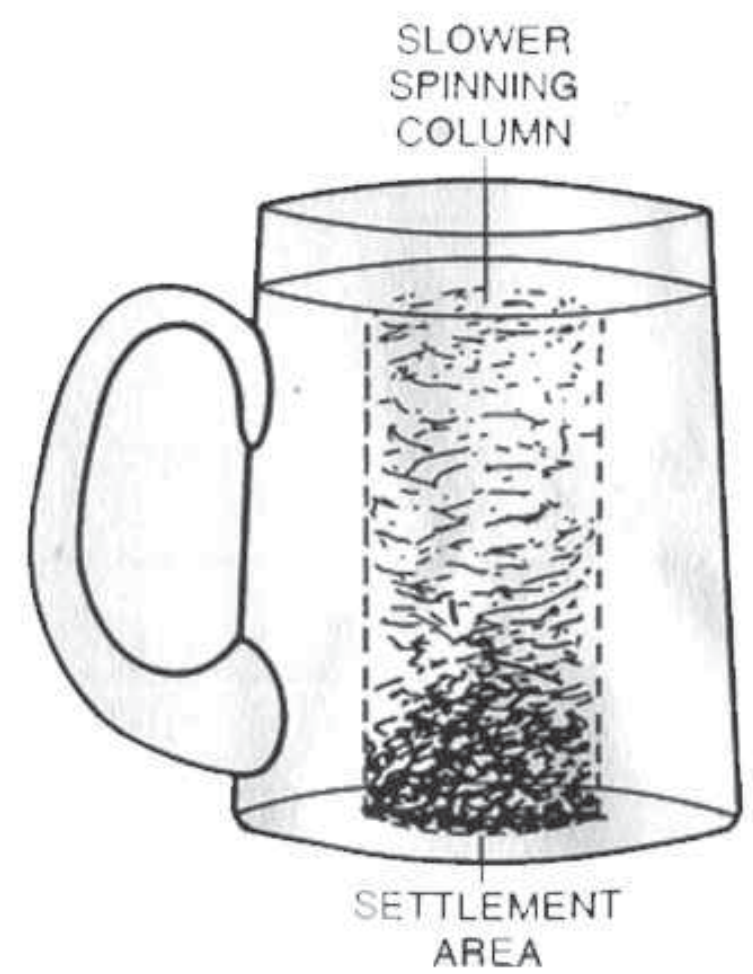

Figure 1: "Tea Cup Effect" simply put 
Figure 2 shows this doughnut phenomenon in reality. But when an orifice (for under-flow drainage) is provided at the bottom the settled matter forms a spiral like path towards the hole. This theory was experienced with different suspended solids (varying densities, size and shape) but the resulting patterns were identical see Figure 3 below.

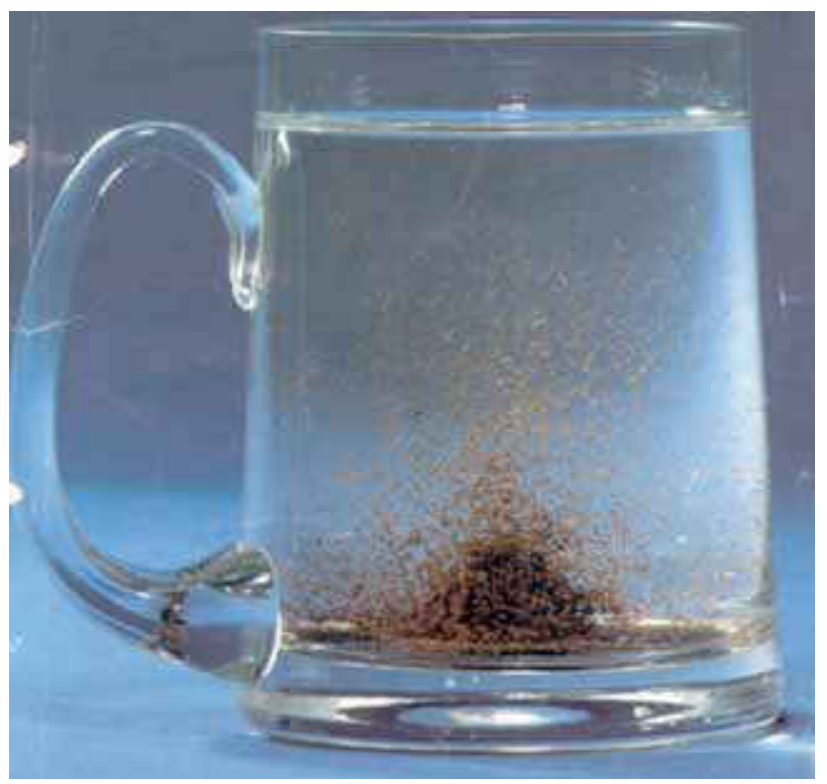

Figure 2: "Tea Cup effect" (Adames, 1988)

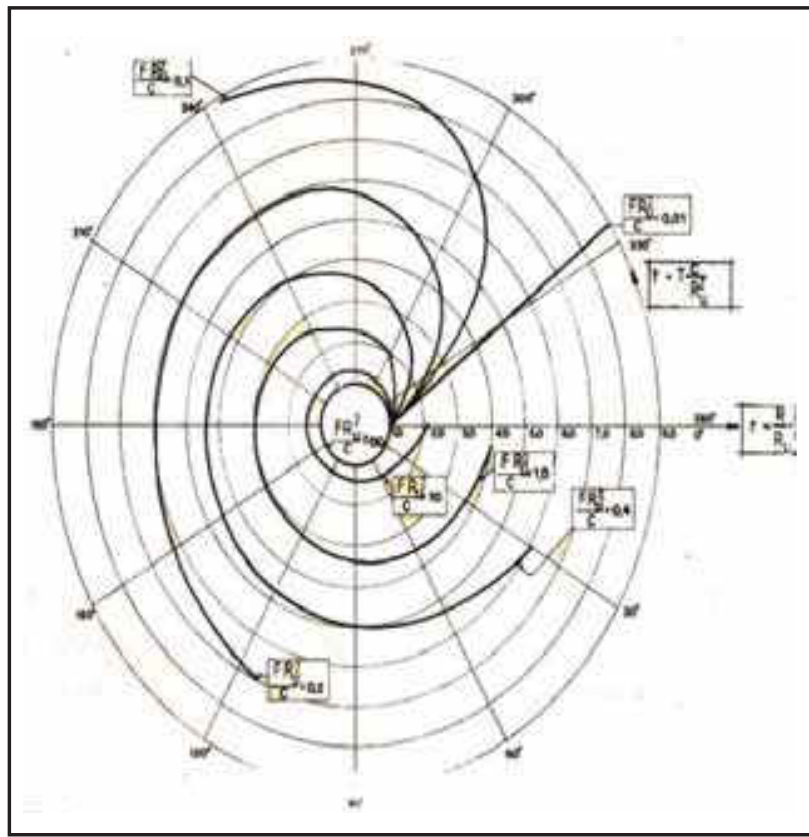

Figure 3: Theoretical spiral paths of particles in a vortex basin (Mashauri, 1986)
The theoretical "Spiral like" paths shown in Figure 3 were almost replicated in reality when different particles (densities and sizes) were subjected to vortex motion in swirl concentrator. A typical pattern is as shown in Figure 4 below. This shows that the "spiral" trajectories are real and not only in theory. Further experiments showed the patterns on the bottom of a swirl concentrator as shown in Figure 5 below. In any case this phenomenon shows how the particles once settled on the bottom move in "spiral" paths towards the central orifice.

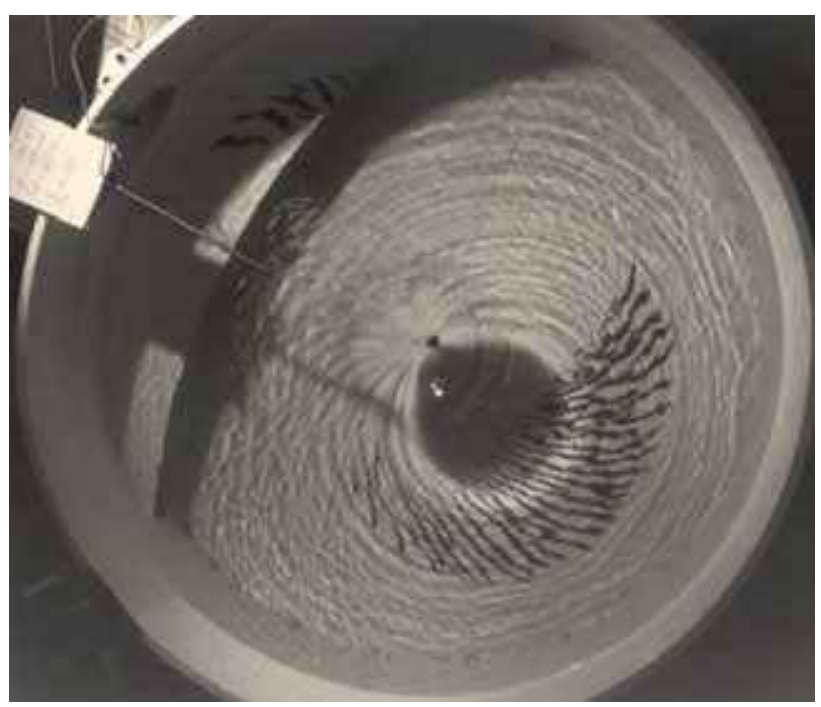

Figure 4: "Spiral like" paths towards the underflow (Mashauri, 1986)

Upon reaching the orifice the settled particles are flushed out as part of the underflow. As mentioned in Mashauri (2008) the underflow should be limited to les than $10 \%$ of the inflow. Again there must be a trade-off between the underflow amount and the removal efficiency one wants to achieve. Please note that the higher the ratio of diameter of basin to diameter of orifice the lower the removal efficiency but less underflow amount. This is only true up to a certain size of particles see Mashauri (2008).

The "Tea Cup effect" is evident in Figure 5 too. The two photos in the middle show the mantle formation and its fading phase. The mantle is basically what we had shown in Figure 1 and was referred to as "shear zone". This is a zone that perpetually has the contents (water and suspended load) in motion with a final downward motion towards the orifice. Indeed any particle that enters this zone is bound be flushed out through the underflow. There is no chance of 
uplifting in this area. This phenomenon happens in large water bodies (seas, lakes and rivers) and is often referred to as sinks. A swimmer or a small boat that has the unfortunate situation of entering such zones is bound to be dragged downwards which can only mean death by drowning!

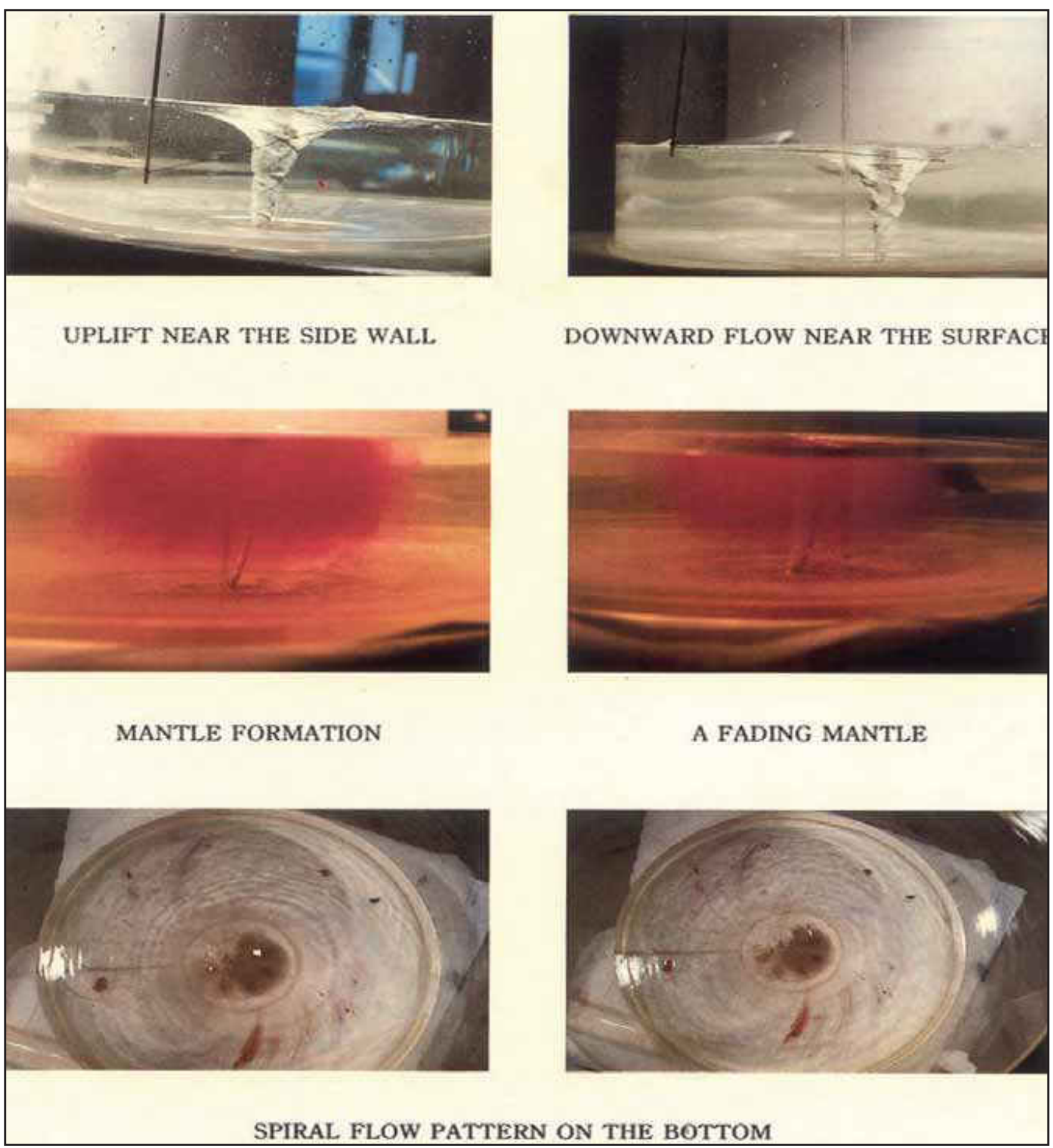

Figure 5: Flow patterns in a swirl concentrator (Mashauri, 1986) 


\section{APPLICATIONS IN PRACTICE}

\section{(i) Smisson approach}

The vortex overflow facility in its simplest features is shown in Figure 6. A pioneer engineer Bernard Smisson, in Bristol, first observed this phenomenon while researching into drop shaft problems. In 1963 he designed and built two storm water overflow devices called Vortex Overflows to retain solids in the sewers while allowing the cleaner overflows to discharge to the River Avon (Smisson, 1967).

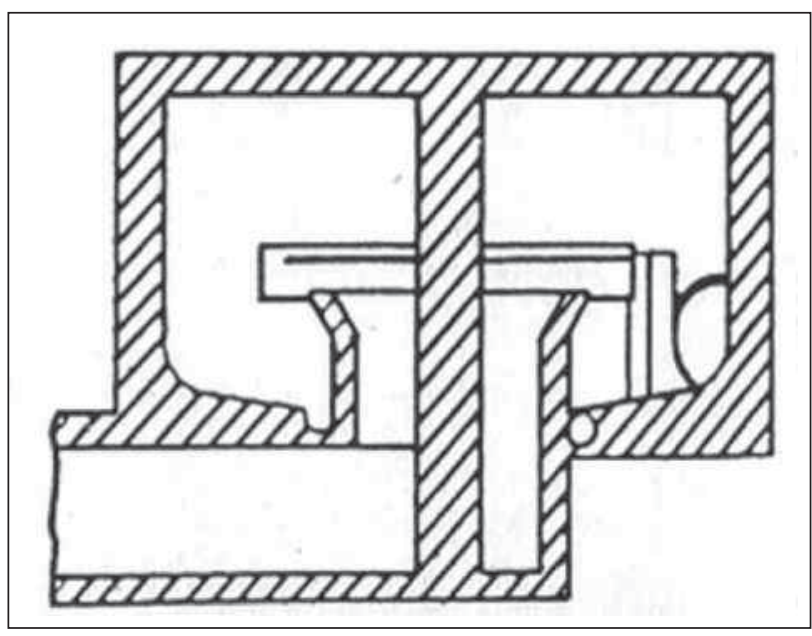

Figure 6: Vortex Overflows (Smisson, 1967)

The approach has resulted in several Vortex overflows facilities built and operated. What is remarkable was that the facilities managed to reduce suspended solids load by over $70 \%$ with only $20 \%$ of the inflow. Experience shows that the facilities have been used effectively, almost trouble free and have required no maintenance at all. Indeed this is what can be applied to our suspended load problems in Tanzania without much modification.

\section{(ii) USEPA approach}

The United States of America Environment Protection Agency (USEPA) borrowed a leaf from the Smisson's work on the vortex overflow facility. USEPA approach developed what is called a swirl concentrator in the 1970s. The Facility (Figure 7) has so far not gained much popularity in practice due to its demand for a high head which is normally not available in storm water drainage problems. However
USEPA developed further the swirl concentrator and the heliconical bend pollution control devices that have functioned fairly well (Sullivan et al 1982).

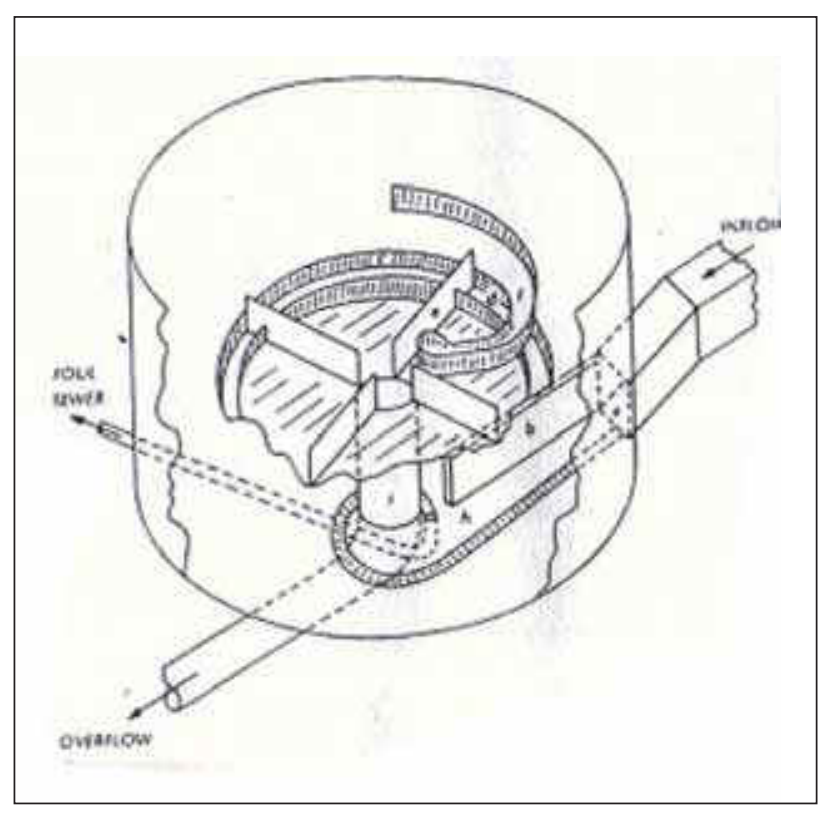

Figure 7: USEPA Swirl Concentrator, (Sullivan, 1972)

\section{(iii) USSR experience}

There are a number of attempts in the same lines in the former USSR. The following is only some of the examples that form part of the success stories.

- 2 Basins Designed for 2 ...... $2.5 \mathrm{~m}^{3} / \mathrm{s}$ (since 1959 working perfectly)

- A series of chambers designed for $15 \mathrm{~m}^{3} / \mathrm{s}$ discharge.

- $\quad$ For the purpose of eliminating sand ahead of irrigation canals and hydropower plants.

\section{(iv) TURKEY experience}

Turkey has tremendous sediment problems. As such they have tried a number of approaches to remove sediment ahead of headrace tunnels for hydropower facilities and in irrigation works. Again here the swirl concentrator has come out as one of the best solutions.

- Hydropower production application

- Basin diameter = $15 \mathrm{~m}$

- Discharge $=5.25 \mathrm{~m}^{3} / \mathrm{s} \bullet$ Inflow area $\quad=\quad 3.06 \mathrm{~m}^{2}$

\}$=>V_{i}=1.71 \mathrm{~m} / \mathrm{s}$ 


$\begin{array}{ll}\text { - } & \text { Bottom slope }=2 \% \\ \text { Under flow diameter }= & 0.6 \mathrm{~m} \quad \succ \\ \mathrm{Db} / \mathrm{Du}=25 \\ \text { Under flow } \mathrm{Qu}=3 \% \mathrm{Qi}\end{array}$

\section{(v) The Grit King approach}

This is a continuation of the earlier version of vortex overflow facilities to have more efficiency. As the name alludes it is a facility to remove grit (sediment, grease and floatable) from water. Trials were carried out to measure the working efficiency of the Grit King. Here, working efficiency is defined as the capability of the device to remove grit or sand particles greater than $0.2 \mathrm{~mm}$ diameter. A one meter diameter Grit King, together with ancillary equipment was set up at a sewage works. Sand/gravel samples, which were weighed and graded before and after each test, were fed into the unit and results obtained were used to calculate the efficiency at the various flow rates. The tests used flow rates from 1.7 litres/sec to 20 litres/ sec and the efficiency various from $99 \%$ at the low flow to $95 \%$ at the high with the average being $97 \%$. The graph below shows the results (Adames, 1988).

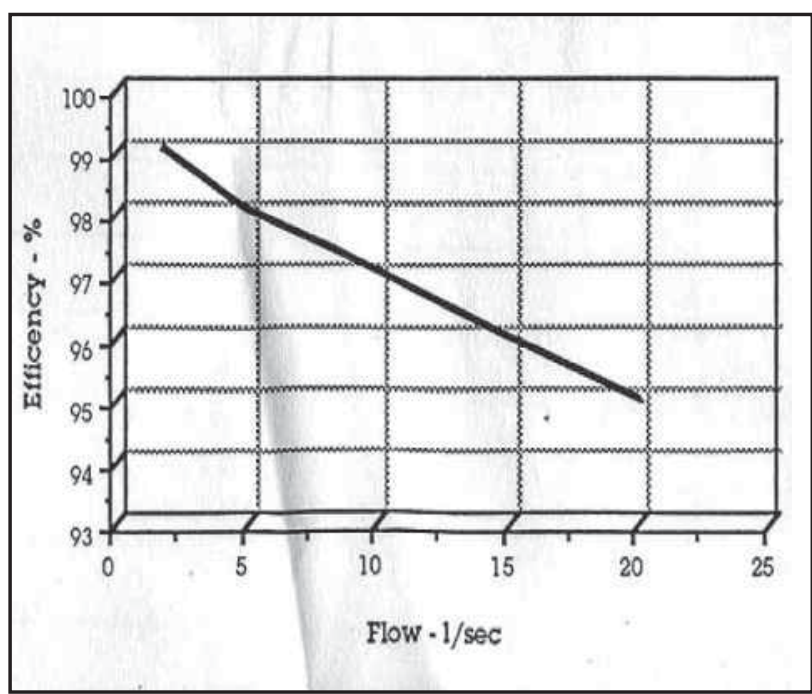

Figure 8: Grit King Performance for particles greater than $0.2 \mathrm{~mm}$ diameter (Adames, 1988)

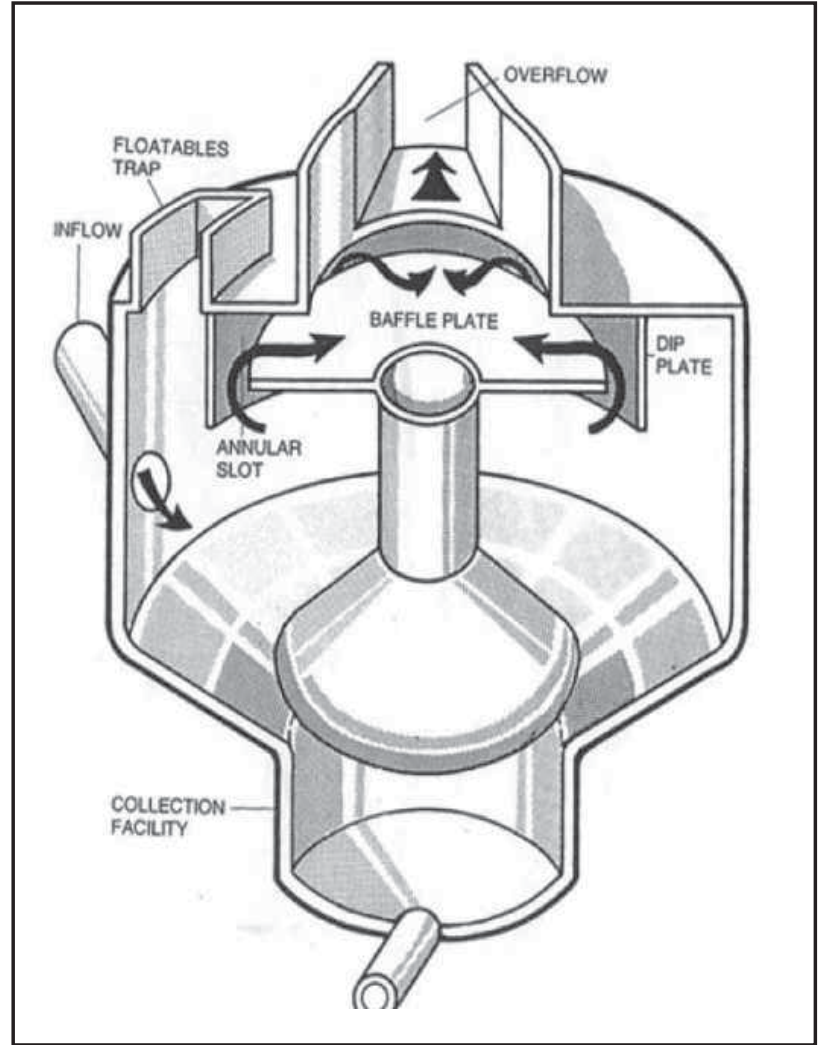

Figure 9: Typical working principles of a Grit King (Adames, 1988)

The simplified diagram (shown in Figure 9) indicates the basic feature found in all separators. Dynamic separators are passive devices and only operate when full. They can be designed to meet a wide variation in site conditions.

The liquid containing the solid for separation is tangentially fed continuously into the side of the separator through the inflow pipe or jet so that the contents rotate gently about the vertical axis; this creates the conditions similar to the flat bottomed glass example previously mentioned. Solids are discharged to the collecting facility underneath the cone. When the flow reaches the top, the now decanted liquid is discharged through the annular slot to the over-flow. Mention should be made of the dip plate's function its location is critical as it assists in stabilizing the position of the "Shear Zone".

Floating materials is gathered in the floatable trap, a feature which is adapted in some applications to remove oil and grease. This feature is very much applicable in Tanzania where intakes may be sited in tropical forests where leaf production is high so floating debris will be a problem to be dealt with. 
(vi) Fish hatchery waste reduction example

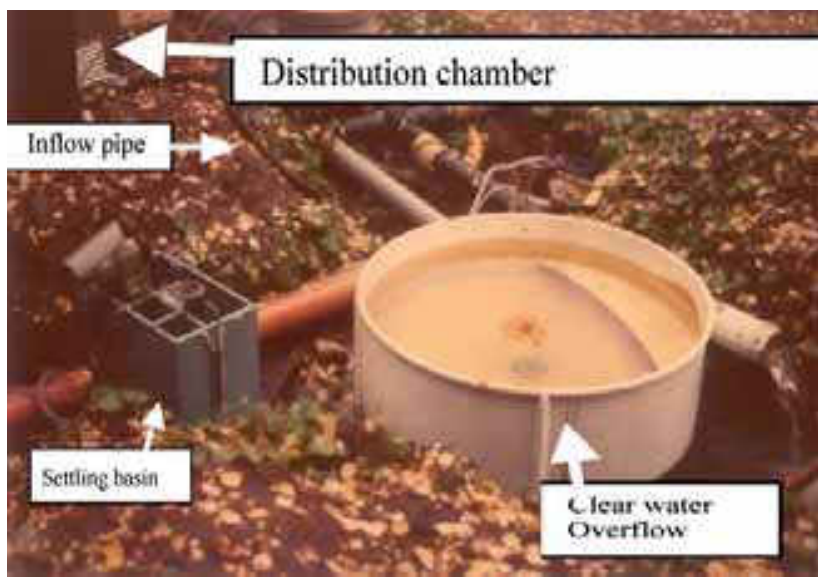

Figure 10: Experiments using a swirl concentrator Fish Hatchery facility in Lammi, Finland, summer 1986 (Mashauri, 1986)

In a fish hatchery a lot of waste is produced in a concentrated area. The waste produced is a made of fish food and excreta at the bottom of large fish hatching facility. The waste consists of nutrients mainly of $\mathrm{N}, \mathrm{P}$ and $\mathrm{K}$ as well as suspended solids. The nutrients are soluble in water so they must be removed before being discharged into receiving water bodies (e.g. Lake, river) downstream of the facilities. A vortex basin (swirl concentrator) is one solution to remove the suspended solids load which to some extent attached to the nutrients mentioned earlier on. In a prototype testing (Mashauri, 1986) over $40 \%$ of the suspended load was removed by such as a basin. It is possible to achieve even better efficiencies if several basins were installed in series (Rantanen and Ryynanen 1985 and Hakkinen et al 1987). The same vortex basin was used to remove polystyrene and plastic pebbles. The particles had varying settling velocities and were subjected to various inflow discharges. In both cases removal efficiency dropped as higher inflows were allowed into the basin. The data is as shown in Figures 11 and 12 below. The results compare fairly well with the Grit King performance shown in Figure 8. As expected the higher the setting velocity the higher the removal efficiency. Indeed in these experiments, though limited to about $10 \mathrm{l} / \mathrm{s}$ inflows the lowest removal efficiency is over $75 \%$ for the heavier particles.

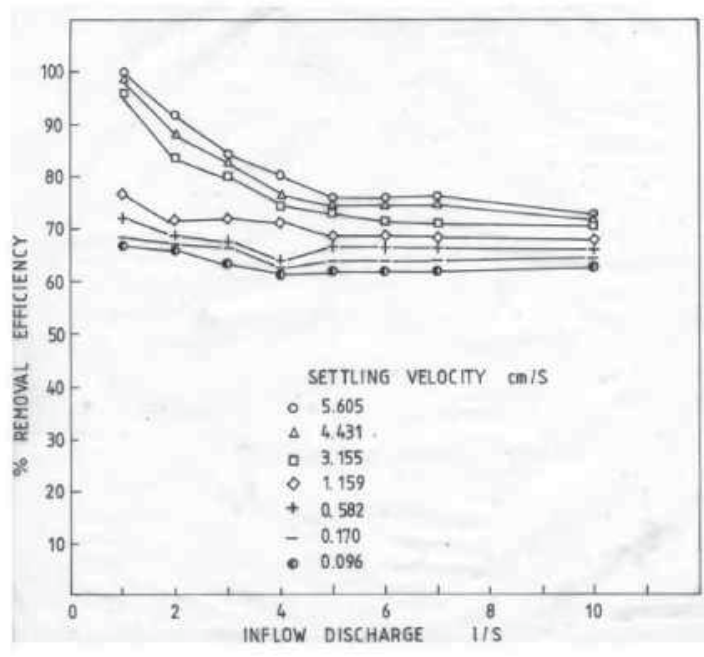

Figure 11: Removal efficiency of plastic pebbles particles (with different settling velocities) versus various inflows discharged (Mashauri, 1986)

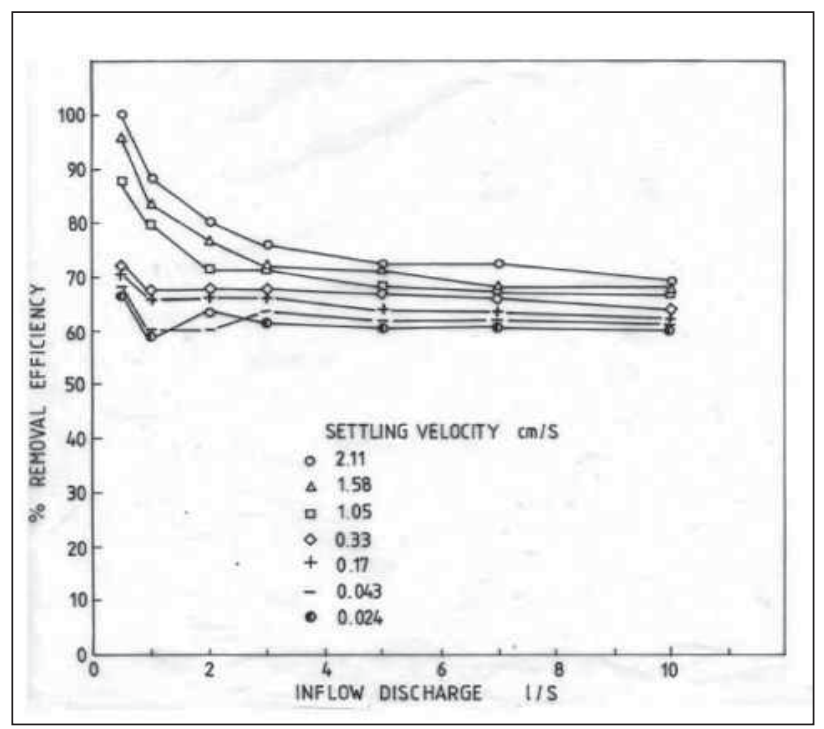

Figure 12: Removal efficiency of polystyrene particles (different settling velocities) versus various inflow discharges (Mashauri, 1986)

\section{(vii) River intake arrangement}

In this typical arrangement, a weir with a gate is constructed across a river to dam-up the water. In this way a desired head is created upstream of the basin which will be the driving force in the settling mechanism. The side curvilinear weir is arranged so as to direct the flow towards the diversion but at the same time removing the coarse particles. (Figure 13.) 


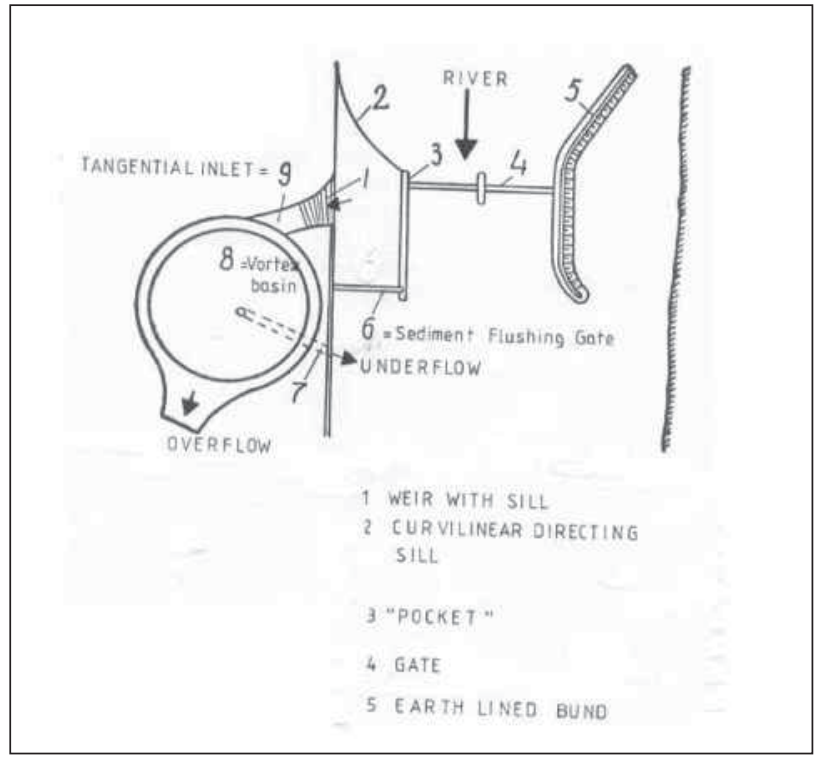

Figure 13: Typical arrangement of swirl concentrator or vortex basin at a river intake.

\section{(viii) Swirl concentrator in series}

In order to improve removal efficient a number of concentrators can be arranged in series as shown in Figure 14. In Hakkinen et al (1987) it was shown that this type of arrangement can achieve higher separation efficiency than a single stage swirl concentrator. This is shown in Figure 15 below

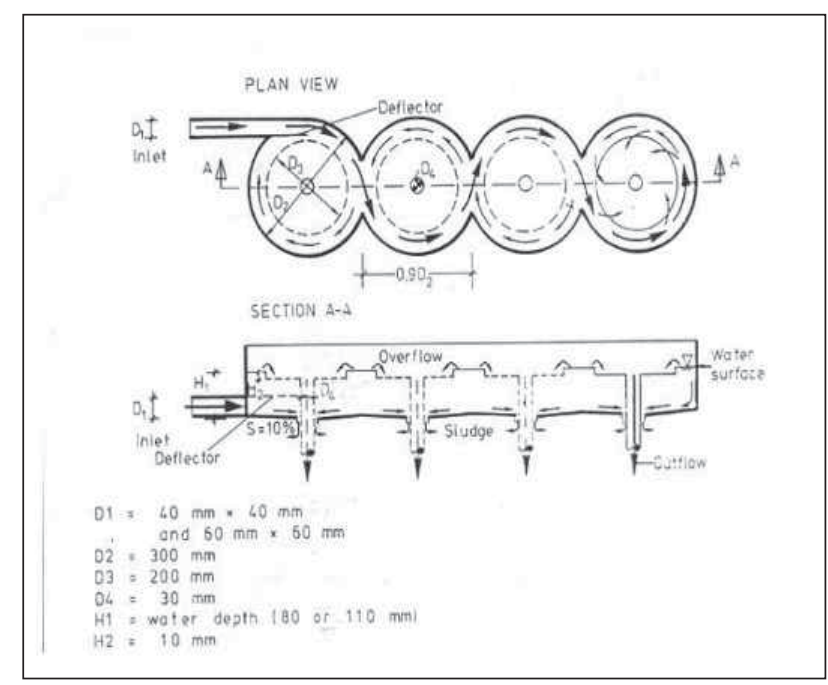

Figure 14: Multi-stage concentrator used in the experiments (Teizazu, 1986)

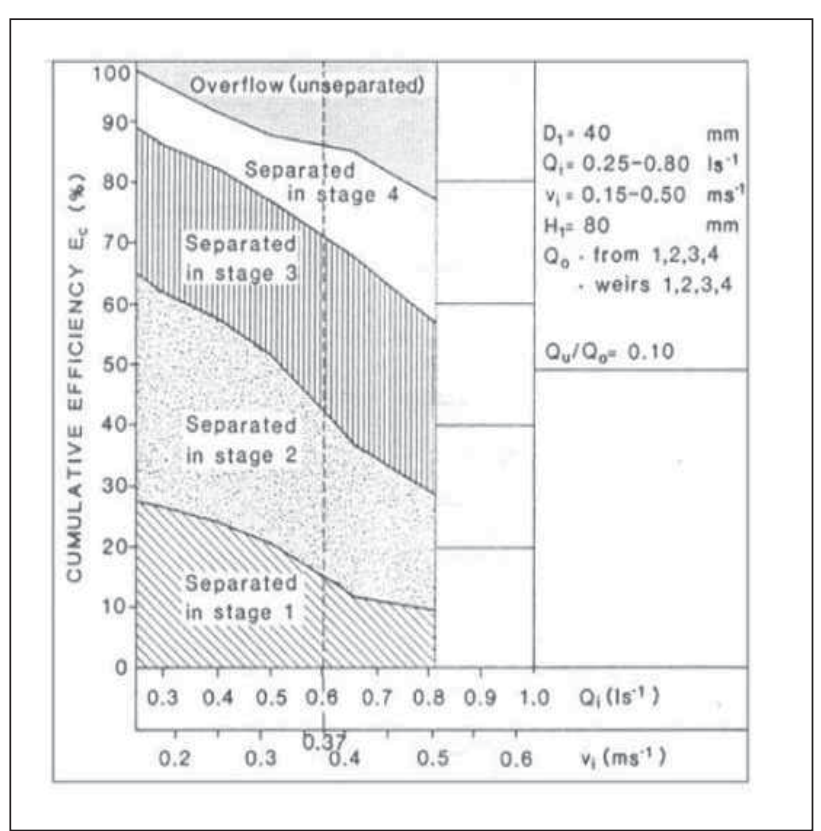

Figure 15: Cumulative efficiency versus inflow and inlet velocity when the overflow is taken from all the stages. (Hakkinen et al, 1987)

It is evident that if overflow is only taken from the last stage (Stage 4) one achieves a better removal. This is clearly shown in Figure 16 below

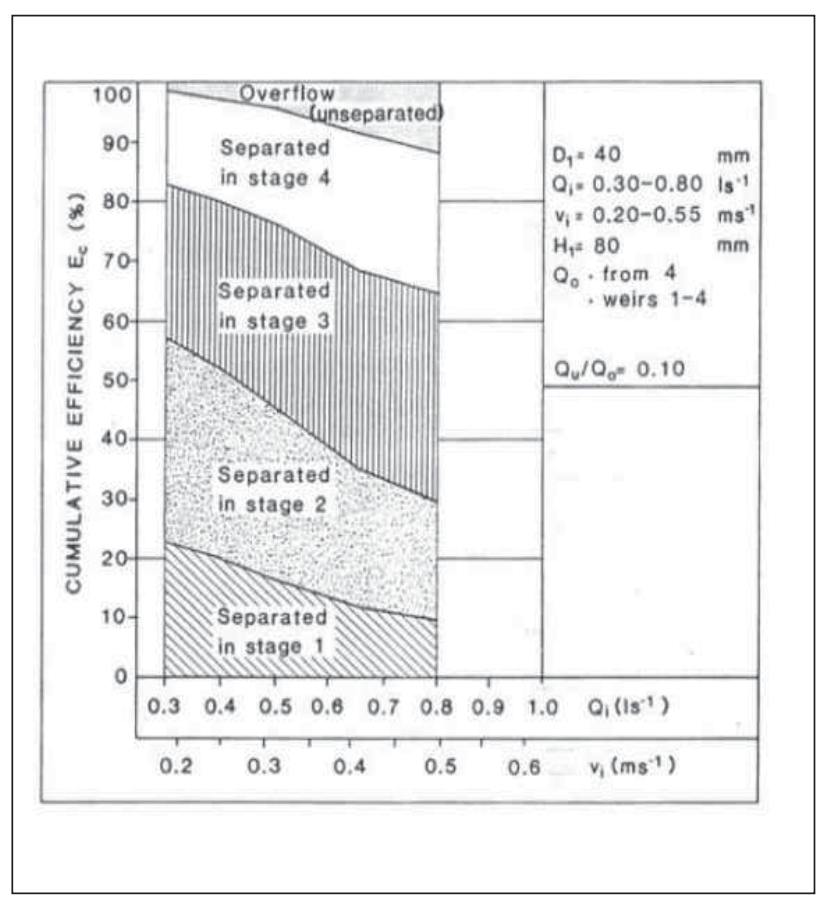

Figure 16: Cumulative efficiency when the overflow is taken only from stage 4. (Hakkinen et al, 1987) 


\section{CONCLUDING REMARKS:}

From this review one can conclude the following;

(i) The "tea cup effect" can be put into use in solids separation processes.

(ii) Solids separation can be effected through simple swirl concentrators without any elaborate appurtenances or any moving parts.

(iii) Overflow vortex facilities have been designed and implemented for almost half a century without much maintenance. Their performance has been excellent and in many cases exceeds $80 \%$ removal efficiencies.

(iv) Swirl concentrators have been used to separate fish waste in fish hatcheries with good removal efficiencies.

(v) A number of examples of these simple but effective basins are in operation in many countries handling discharges up to $15 \mathrm{~m}^{3} / \mathrm{s}$.

(vi) If higher removal efficiencies are desired then basins can be arranged in series to achieve this. Indeed this has been shown to be a possible solution to waste water treatment process.

\section{REFERENCES:}

Adames, Mike, (1988),

Grit King, Dynamic Separation for separating solids from Liquids, Hydro Research and Development, A502, $4 \mathrm{p}$

Hakkinen, R., Katko, T.S., Ryynanen, S., and Teizazu, T., (1987),

Developing a multistage swirl concentrator for highest separation efficiencies filtration and separation, Vol. 24, No. 6, pp.44-416
Mashauri, D.A., (1986)

Modelling of a Vortex Settling Basin for Primary Clarification of Water. Tampere University of Technology. Doctoral Dissertation, Publication No. A 42 Tampere, Finland.

Mashauri, D.A., (2008),

Simple but appropriate Design Procedure for a Vortex Setting Basin, The Tanzania Engineer, Vol. 8 No. 4, pp 64-72.

Rantanen, S., and Ryynanen, S., (1985).

Multi-Stage Centrifugal Classification Process in Grinding Circuits. 15th International Mineral Processing Congress 15. Cannes.

Smisson, B., (1967),

Design, construction and Performance of Vortex Overflow Regulator. Symposium on Storm Sewage Overflows. Proceedings of Institute of Civil Engineers. London.

Sullivan, R.H., (1972)

Swirl Concentrator as a combined Sewer Overflow Regulator. America Public Works Association for EPA. Chicago.

Sullivan, R.H., Ure, J.f., Parkinson, F.E., and Zielinski, P.E. (1982).

Swirl and Heliconical Bend Pollution Control Devices. American Public Works Association for EPA. Chicago.

Teizazu Tilahun, (1986).

Swirl Basin of Series Unit in Solids Separation. Tampere university of Technology, Section of Water and sanitation engineering, M.Sc. Eng. Dissertation, Publication No. B. 19, Tampere, Finland. 